\title{
Performance assessment and optimization of a helical Savonius wind turbine by modifying the Bach's section
}

\author{
M. Niyat Zadeh ${ }^{1} \cdot$ M. Pourfallah ${ }^{1}$ (D) S. Safari Sabet ${ }^{1} \cdot$ M. Gholinia $^{2} \cdot$ S. Mouloodi ${ }^{3} \cdot$ A. Taheri Ahangar ${ }^{1}$
}

Received: 29 January 2021 / Accepted: 7 July 2021

Published online: 14 July 2021

(c) The Author(s) 2021 OPEN

\begin{abstract}
In this paper, we attempted to measure the effect of Bach's section, which presents a high-power coefficient in the standard Savonius model, on the performance of the helical Savonius wind turbine, by observing the parameters affecting turbine performance. Assessment methods based on the tip speed ratio, torque variation, flow field characterizations, and the power coefficient are performed. The present issue was stimulated using the turbulence model SST (k- $\omega)$ at 6,8 , and $10 \mathrm{~m} / \mathrm{s}$ wind flow velocities via COMSOL software. Numerical simulation was validated employing previous articles. Outputs demonstrate that Bach-primary and Bach-developed wind turbine models have less flow separation at the spoke-end than the simple helical Savonius model, ultimately improving wind turbines' total performance and reducing spoke-dynamic loads. Compared with the basic model, the Bach-developed model shows an 18.3\% performance improvement in the maximum power coefficient. Bach's primary model also offers a $12.4 \%$ increase in power production than the initial model's best performance. Furthermore, the results indicate that changing the geometric parameters of the Bach model at high velocities (in turbulent flows) does not significantly affect improving performance.
\end{abstract}

Keywords Helical Savonius · Bach's primary model · Bach's developed model · Power and torque coefficient

\section{Introduction}

Energy has an essential role in solving problems to achieve sustainability and development of different countries [1]. Work to obtain the required energy enjoys a direct correlation with productivity and economic development. So far, remarkable progress in conjunction with renewable energy has been made [1, 2]. Solar, wind, wave, and geothermal energies are among the most important renewable energies. Wind energy is considered one of the newest growing electricity production resources [3]. The reason for this widespread attraction is due to various advantages offered by wind energy. Some of the advantages are offering clean energy, high stability, low cost, etc. Additionally, wind turbine plants use minimal water and occupy less land compared to other electricity production plants [4, 5]. Wind energy is significant due to rapid technological advances, the competitive space of wind turbine manufacturers, and their production's quantitative increase levels. Although the initial investment for purchasing and installing wind turbines may be high, their rate of return is considerable. Since many parameters influence wind turbines' performance, not many studies have been conducted on wind turbines' different types and geometries [6]. For example, Koroneos [7] analyzed energy and exergy for a wind energy system for the first time. Baskut et al. [8] measured the difference between energy and exergy efficiency for three turbines in the Cesne and Izmir wind sites.

$\triangle$ M. Pourfallah, m.pourfallah@ustmb.ac.ir|'Department of Mechanical Engineering, Mazandaran University of Science and Technology, Babol, Iran. ${ }^{2}$ Department of Mechanical Engineering, Babol Noshirvani University of Technology, Babol, Iran. ${ }^{3}$ Department of Mechanical Engineering, The University of Melbourne, Melbourne, Australia.

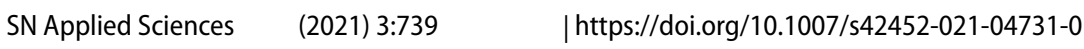


They concluded that the turbines' exergy efficiency has changed during different periods of the year by between 0 and $68.2 \%$. Sagol et al. [9] reviewed the effect of the surface roughness on the wind turbine blade on aerodynamic performance and turbine power generation. Pope et al. [10] also analyzed the exergy flow of four wind turbine models (two vertical and two horizontal axes). This study investigated different wind flow velocity changes, temperature, and pressure changes on wind turbines. Moreover, Khalfallah and Koliub [11] studied the effects of dust particle roughness on wind turbine power production in a desert site. Further examples of the latest research pointing out the importance of this issue can be found in references $[12,13]$.

Savonius wind turbines offer advantages, such as high torque, simple design, and working capability in the wind flow direction, although having less aerodynamic efficiency [14]. Savonius wind turbines are widely used on a micro- and small scale, such as producing domestic and residential electricity. However, what makes spiral Savonius wind turbines different from their standard counterparts is that the spiral model has a positive torque coefficient for all rotor angles, enabling better performance than traditional Savonius wind turbines [15]. Also, many studies have been conducted on investigating Savonius turbines experimentally and numerically to improve this type of turbine's performance. In a comprehensive study conducted by Akwa et al. [16] on Savonius wind turbine structure, different kinds of Savonius wind turbines were studied in detail. Their advantages and disadvantages and wind flow effect on performance were identified. In a study conducted by Roy and Saha [17], a two-spoked Savonius wind turbine with different sections such as semicircle, oval, Bach, and Benesh was investigated in the wind tunnel. Studying the spoke's aerodynamic behavior using various Reynolds numbers, it was found that correctly establishing the wind turbine sections may result in an improved power output of up 35\%. Ricci et al. [18] investigated a Savonius vertical-axis wind turbine (VAWT) numerically, aiming to improve the performance of a spiral wind turbine for a passage lighting system. The study concluded that blocking the higher and lower parts of the spokes with circular sheets and overlapping spokes at the rotor center increases turbine efficiency. Jeon et al. [19] studied the effects of changing the shape of the first and last sheets of helical turbine spokes on wind turbine performance. They concluded that the last circular sheets with more than one coverage coefficient provide the best option in increasing efficiency for this wind turbine model. Driss et al. [20] focused on the geometry of the section within Savonius turbines' in optimizing turbine rotor performance. They concluded that increasing the spoke's circular curvature also increases pressure drops.
This study aims at stimulating an example of VAWT for a helical Savonius type at three different wind velocities $(6,8$, and $10 \mathrm{~m} / \mathrm{s})$ using COMSOL software. Therefore, the decision was made to measure helical Savonius wind turbines by considering effective parameters on the performance of the turbine (the effect of rotor upper and lower sheets, helical vertical-axis turbine torsion angle, and Bach's section effect) and reporting the improvement of helical Savonius wind turbines compared with the circular spiral model.

\section{Wind turbine under investigation}

The wind turbine studied in this research is a helical Savonius vertical-axis wind turbine, and it is considered to be made up of fiberglass-based on the study by Jeon et al. [19]. Figures 1 and 2 show the schema of this turbine. This turbine includes two spokes with a semicircular section and $180^{\circ}$ rotation angle, as well as circular covering sheets at the top and the bottom of the wind turbine rotor. Table 1 shows the full information of the geometrical dimensions of this turbine. Savonius wind turbines have many advantages such as high torque, simple design, and capability of operation in any wind direction, although they have limited aerodynamic performance. Savonius wind turbines are extensively employed in small scale such as domestic and residential power generation; however, what causes the superiority of the helical Savonius wind turbine relative to its conventional model is that the helical model has a positive torque coefficient for all rotor angles that this feature causes to have better performance compared to conventional Savonius wind turbines.

First, the turbine mentioned in reference [19] was stimulated using the turbulence model SST $(k-\omega)$ at 6 , 8 , and $10 \mathrm{~m} / \mathrm{s}$ wind flow velocities via COMSOL software. Then, after validating the results from changing the
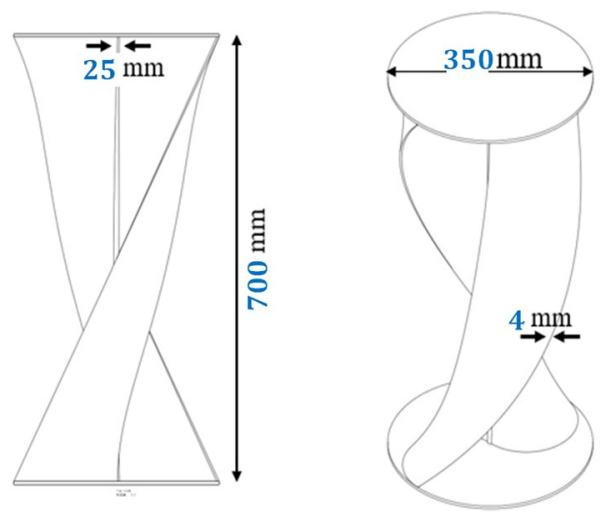

Fig. 1 Schematic of Savonius helical wind turbine 
Fig. 2 a Schematic of the improved Bach model; b Schematic of the Bach model

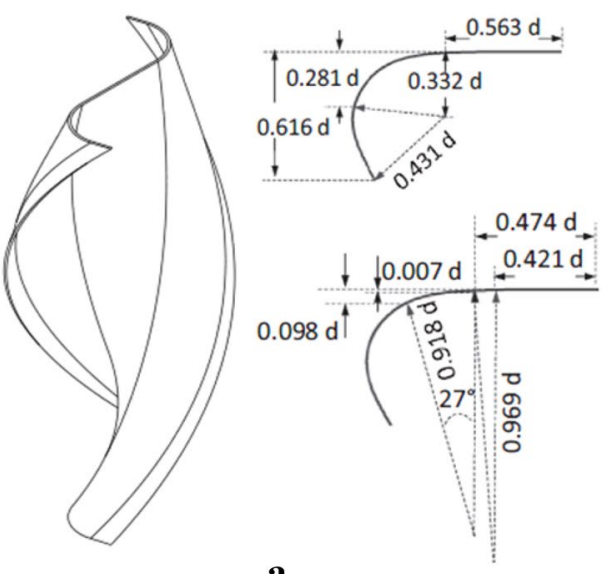

a

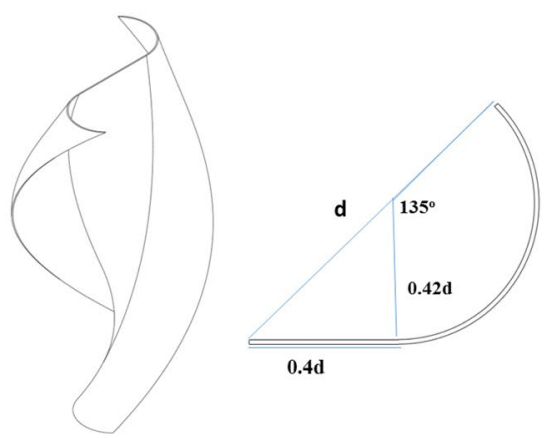

b
Table 1 Geometric specifications of wind turbines

\begin{tabular}{ll}
\hline Geometry & Dimensions \\
\hline Rotor length & $700 \mathrm{~mm}$ \\
Rotor diameter & $350 \mathrm{~mm}$ \\
Shaft diameter & $25 \mathrm{~mm}$ \\
Blade thickness & $4 \mathrm{~mm}$ \\
Square width & $4200 \mathrm{~mm}$ \\
Square length & $10,150 \mathrm{~mm}$ \\
Square height & $4200 \mathrm{~mm}$ \\
\hline
\end{tabular}

wind turbine section into two Bach and Bach-developed models, the behavior of the wind turbine was investigated and compared with parameters such as the output power factor, production torque coefficient, velocity, and pressure contours in the environment.

\subsection{Mathematical equations}

The primary relationships for calculating the parameters affecting the performance of wind turbines are as follows:

\section{Equations}

$\lambda=\frac{\Omega \cdot R}{U_{\infty}}$

Tip speed ratio of the blade $(\lambda)[4,21]$

( $R$ is the radius of the rotor, $\Omega$ is the angular velocity of the rotor, and $U \infty$ is the velocity of fluid.)

$C_{P}=\frac{P_{r}}{0.5 \rho A U_{\infty}^{3}}$

The power coefficient or $\left(C_{P}\right)[4,21]$

The torque coefficient or $\left(C_{T}\right)[4,21]$

( $\mathrm{P}_{\mathrm{r}}$ is the turbine power, $\rho$ is the fluid density and $\mathrm{A}$ is the area swept.)

$C_{T}=\frac{M_{r}}{0.5 \rho A U_{\infty}^{2} R}$

$\left(\mathrm{M}_{\mathrm{r}}\right.$ is the turbine torque.)

The relevance between torque coefficient and power coefficient $[4,21]$

$C_{P}=\lambda C_{T}$ 


\subsubsection{Continuity equation for turbulent flow}

Differential form of continuity equation is written in the form of Eq. (1) [22]:

$\frac{\partial \rho}{\partial t}+\frac{\partial}{\partial x_{i}}\left(\rho u_{i}\right)=0$

Equation (1) for the instantaneous values of the turbulent flow is established. If time averaging is performed by Eq. (1), the continuity equation for turbulent flow is expressed in the form of Eq. (2) by putting the instantaneous values with time-average values and fluctuation values, as well as Reynolds averaging rules [22]:

$\frac{\partial \bar{\rho}}{\partial t}+\frac{\partial}{\partial x_{i}}\left(\bar{\rho} \bar{u}_{i}{ }_{i}\right)+\frac{\partial}{\partial x_{i}}\left(\bar{\rho}^{\prime} \bar{u}_{i}{ }_{i}\right)=0$

Because $\rho^{\prime}=0$, Eq. (2) will be in the form of Eq. (3) for an incompressible flow [22]:

$\frac{\partial \overline{u_{i}}}{\partial x_{i}}=0$

\subsubsection{Momentum equation for turbulent flow}

The momentum equation for incompressible flow with constant viscosity is in the form of Eq. (4) [23].

$\rho\left(\frac{\partial u_{i}}{\partial t}+u_{j} \frac{\partial u_{i}}{\partial x_{j}}\right)=-\frac{\partial p_{i}}{\partial x_{i}}+\mu \frac{\partial^{2} u_{i}}{\partial x_{j} \partial x_{j}}+S_{i}$

It should be noted that Eq. (4) is valid for both laminar and turbulent flows. However, dependent variables such as speed and pressure are time-dependent for a turbulent flow. After performing a series of mathematical operations and necessary simplifications, the momentum equation for turbulent flow is expressed in the form of Eq. (5) [24].

$\rho\left(\frac{\partial \bar{u}_{i}}{\partial t}+\bar{u}_{j} \frac{\partial \bar{u}_{i}}{\partial x_{j}}\right)=-\frac{\partial \bar{P}}{\partial x_{i}}+\frac{\partial}{\partial x_{j}}\left(\mu \frac{\partial \bar{u}_{i}}{\partial x_{j}}-\rho \bar{u}_{j}{ }_{j} \bar{u}_{i}{ }_{i}\right)+S_{i}$

Model $k$ - $\omega$ SST was introduced by Menter [25] in order to combine the accurate and powerful formulation of model $k$ - $\omega$ with model $k-\varepsilon$ since the model $k$ - $\omega$ gives good results near the wall and the model $k-\varepsilon$ independent of free flow in areas far from the wall [26]. Simultaneously, this model has the high ability of the model $k-\omega$ in areas with low Reynolds number and the proper ability of model $k-\varepsilon$ in areas with high Reynolds number. By examining recent studies in turbulent flow modeling around vertical-, horizontal-axis wind turbines and even flow simulation around aerators employed in wind

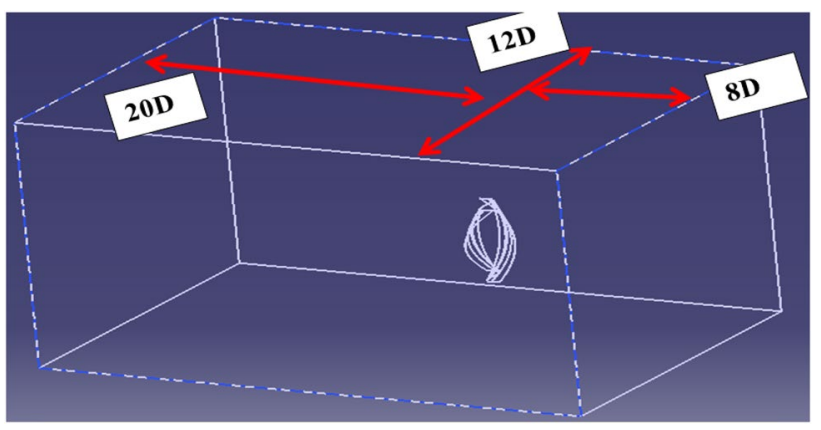

Fig. 3 General geometry for simulation (or the domain of the problem)

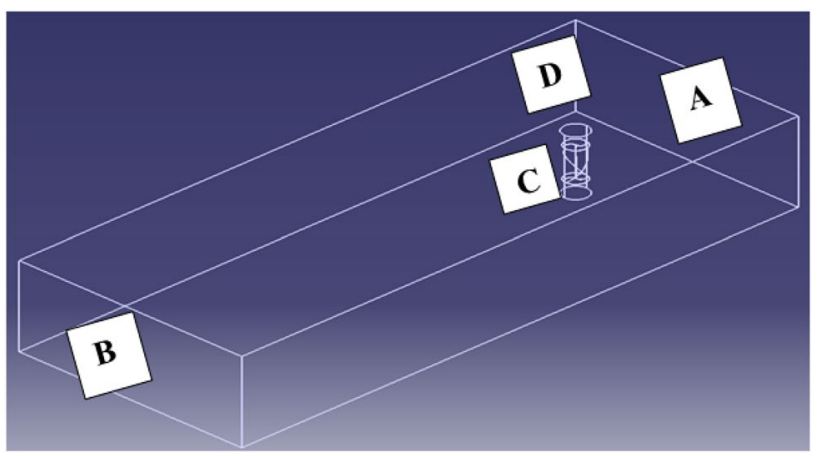

Fig. 4 Schematic diagram of the boundary conditions applied to the problem

turbines, it can be evidently understood that $k-\omega$ SST model produces acceptable and satisfactory solutions.

\section{Boundary conditions}

Figures 3 and 4 show the domain of the problem and an overview of the points which are defined as initial conditions.

\subsection{Inlet Boundary Condition}

According to Fig. 4, velocity inlet conditions have been considered for level $\underline{A}$ in the current modeling.

\subsection{Outlet Boundary Condition}

The pressure outlet border condition has been considered for the outlet sheet (level $\underline{B}$ in Fig. 4). In this border condition, relative pressure in the border plus the 
Table 2 Results for grid independence checking

\begin{tabular}{llll}
\hline Number & $\begin{array}{l}\text { Velocity inlet } \\
(\mathrm{m} / \mathrm{s})\end{array}$ & $\begin{array}{l}\text { Total number of } \\
\text { mesh cells }\end{array}$ & $\begin{array}{l}\text { Torque coefficient } \\
\text { applied to the rotor }\end{array}$ \\
\hline 1 & 6 & $1,932,145$ & 16.0 \\
2 & 6 & $2,132,982$ & 21.0 \\
3 & 6 & $3,332,874$ & 24.0 \\
4 & 6 & $4,003,955$ & 25.0 \\
\hline
\end{tabular}

turbulence information of the backflow are considered in the state where the flow enters the border.

\subsection{Wall Condition}

Wall condition has been considered for all wind turbine components, including rotor parts (level $\underline{\mathrm{C}}$ in Fig. 4). In this condition, surface roughness and the no-slip condition are specified. In the default model, wind flow components are equal to zero on this border, considering the no-slip condition.

\subsection{Periodic Condition}

The spoke enclosing cylinder (level $\underline{D}$ in Fig. 4) has a periodic property due to the rotation of the turbine. Therefore, the periodic border condition was considered.

\subsection{Interior Levels Condition}

All interior levels that are not rigid geometry designed to lessen networking around objects are within the interior level border condition category. This border is practically a part of fluid space, and the flow passes through without change.
Table 3 Comparison of production torque coefficient between simulation results and wind tunnel at $8 \mathrm{~m} / \mathrm{s}$

\begin{tabular}{llll}
\hline Tip speed ratio & Past studies [15] & CFD simulation & $\begin{array}{l}\text { Relative } \\
\text { error rate } \\
(\%)\end{array}$ \\
\hline 2.0 & 245.0 & 252.0 & 8.2 \\
6.0 & 192.0 & 202.0 & 2.5 \\
1 & 042.0 & 05.0 & 19 \\
\hline
\end{tabular}

Table 4 Comparison of production power coefficient between simulation results and past studies at $8 \mathrm{~m} / \mathrm{s}$

\begin{tabular}{lccl}
\hline Tip speed ratio & Past studies [15] & CFD simulation & $\begin{array}{l}\text { Relative } \\
\text { error rate } \\
(\%)\end{array}$ \\
\hline 2.0 & 05.0 & 053.0 & 6 \\
6.0 & 123.0 & 128.0 & 4 \\
1 & 056.0 & 061.0 & 9.8 \\
\hline
\end{tabular}

\section{Grid independence checking}

In this study, different stimulations were completed by producing mesh in various dimensions and sizes. The torque produced by the rotor in each mesh is measured until the increasing number of mesh nodes does not significantly influence torque. This process firstly began with a larger mesh and gradually finished with finer ones. Table 2 shows the specifications of the system used in this study. According to Table 2, the torque coefficient in mesh $\mathbf{3}$ and $\mathbf{4}$ has a minimal difference. Therefore, it is possible to use mesh number $\mathbf{3}$, which is the basis of the current stimulation. (See Fig. 5).

\subsection{Validation}

To validate the information from the stimulations, initially, the results of the torque coefficient and the spiral Savonius model's power, with a circular section, were compared with the results out of the values extracted from the wind
Fig. 5 The schematic of domain discretization (meshing)
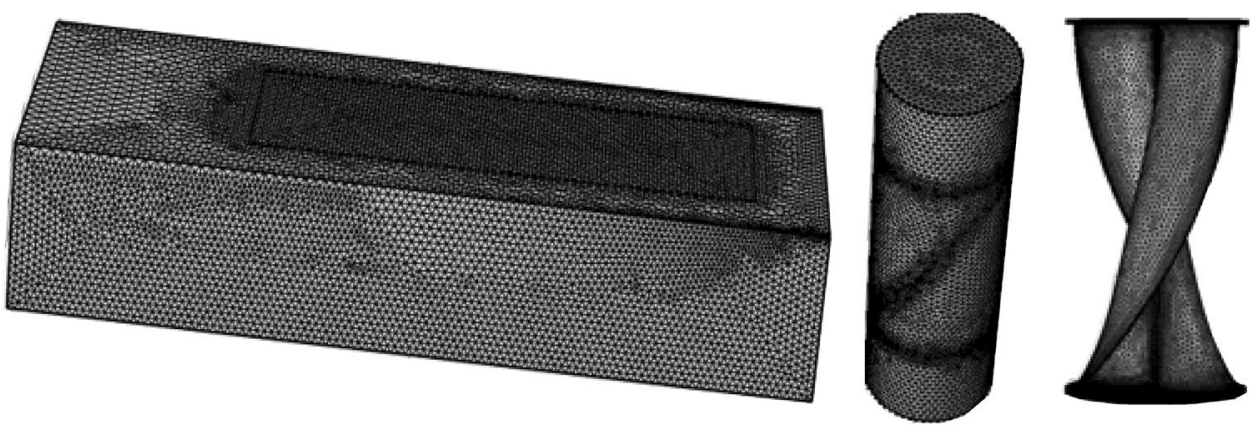

SN Applied Sciences A SPRINGer NATURE journal 


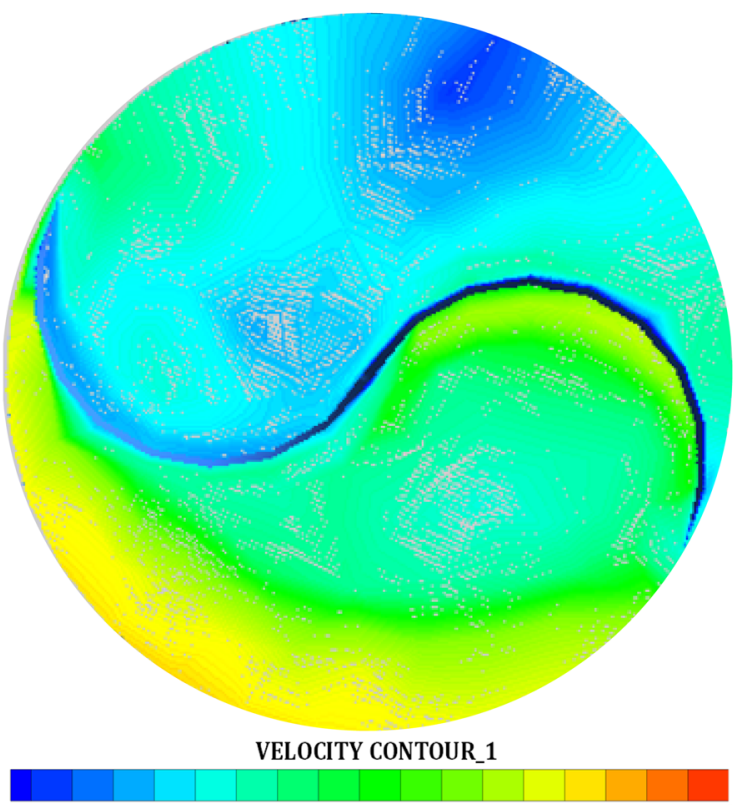

0.000 .840 .961 .451 .932 .422 .903 .393 .874 .364 .845 .335 .816 .306 .787 .277 .75

a Wind flow around a simple helical Savonius turbine.

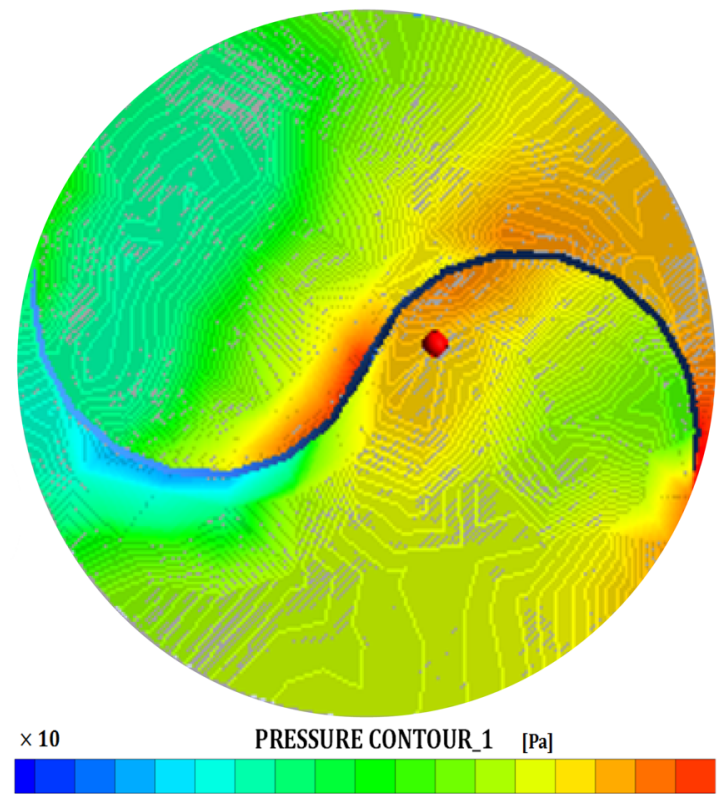

$\begin{array}{llllllllllllllllll}-5.0 & -4.5 & -4.1 & -3.7 & -3.3 & -2.8 & -2.4 & -2.0 & -1.6 & -1.1 & -0.07 & -0.03 & 0.09 & 0.51 & 0.93 & 1.36 & 1.78\end{array}$

b Air pressure around a simple helical Savonius turbine.

Fig. 6 a Wind flow around a simple helical Savonius turbine; b Air pressure around a simple helical Savonius turbine

tunnel in the study conducted by Jeon et al. [19] in Tables 3 and 4 , the data are shown at $8 \mathrm{~m} / \mathrm{s}$ wind velocity in three different tip speed ratios of $0.2,0.6$, and 1 . By comparing the results, it can be determined that there is an acceptable agreement between the simulation results and the results extracted from the wind tunnel.

\section{Results and discussion}

\subsection{Velocity and pressure}

Figures 6 (a-b) has dealt with the post-process CFD information at a $6 \mathrm{~m} / \mathrm{s}$ wind velocity and $50 \mathrm{rpm}$ rotational speed in COMSOL software to investigate the simple helical aerodynamic characteristics of the Savonius model. These variables are air velocity around the blade and wind flow pressure around the wind turbine, respectively. Considering the wind flow's value and the spoke rotation, the wind flow velocity pattern is perfectly different in the spoke's right half from wind flow velocity in the left half. This diverse pattern will change the pressure contour in each half of the spoke, creating torque in the spokes' rotation direction. Therefore, forward to the section studied in Figs. 6 (a-b), the more commonly pressure and velocity patterns are divided into both sides of the spoke. This results in the vertical forces on the rotor that fatigue the system being more controllable and increasing torque coefficient and power in the turbine.

Figures $7(a-b-c)$ investigates the pressure pattern of the spoke within simple helical Savonius wind turbines, primarily the Bach model and Bach-developed model at 6,8 , and $10 \mathrm{~m} / \mathrm{s}$ wind flow velocities. As illustrated, an increased pressure gradient on the two spokes' surface creates more torque around the turbine axes. According to these figures, each part of the spoke's pressure pattern is entirely different due to rotation along the spoke, making the investigation of turbine behavior complicated. Furthermore, in the Savonius model, compared to the other two models, the pressure difference in both parts of the blade is more negligible, which reduces the output torque. In contrast, this pressure gradient is seen more often in the Bach-developed model.

In addition, while investigating wind flow patterns behind the wind turbines under investigation in Figs. 8 (a-b), most wind velocity gradient changes are behind the turbine in simple helical Savonius wind turbines. This disruption in the lower side wind flow pattern is more significant due to the separation of wind flow from the spokes' ends, creating reverse pressure behind the spoke. Therefore, designing spokes precisely postpones separation in the turbine. According to the figures, a simple helical Savonius wind turbine has zero wind velocity at the right half of the spoke's end, which results in flow separation at the end of the spoke. Compared with Fig. 8b, the separation 


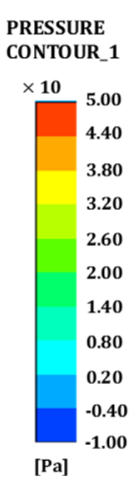

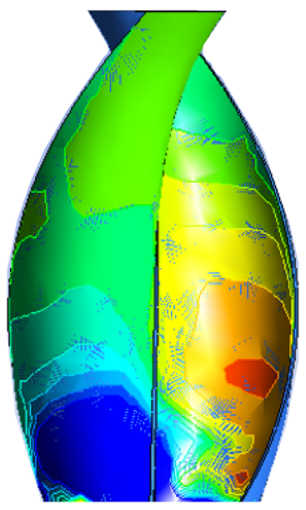

Savonius model

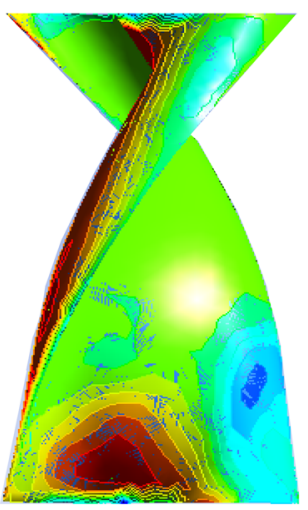

Bach's primary model

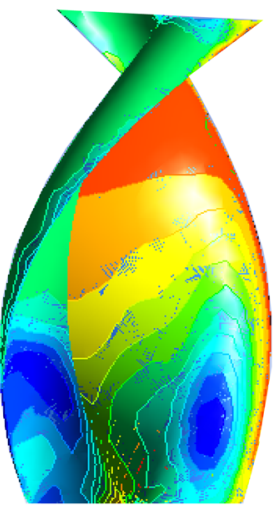

Bach's developed model

a Pressure contour on wind turbine blade at wind speed of $6 \mathrm{~m} / \mathrm{s}$ and rotational speed $75 \mathrm{rpm}$

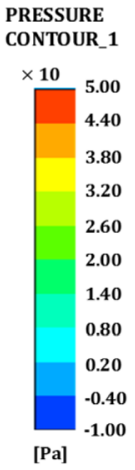

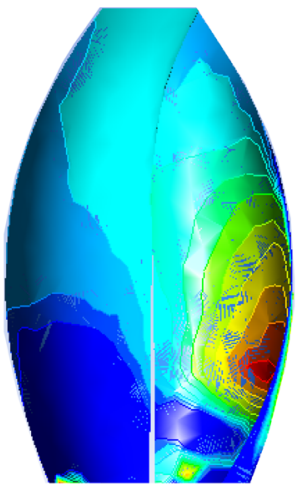

Savonius model

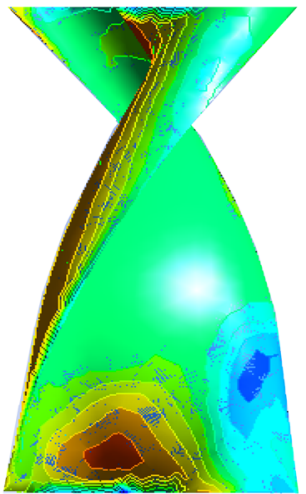

Bach's primary model

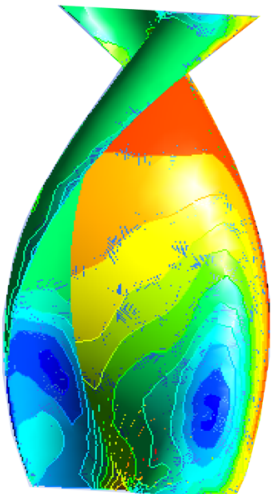

Bach's developed model

b Pressure contour on wind turbine blade at wind speed of $8 \mathrm{~m} / \mathrm{s}$ and rotational speed $150 \mathrm{rpm}$

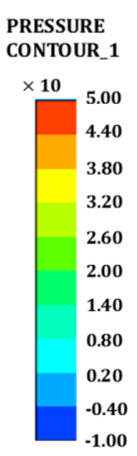

[Pa]

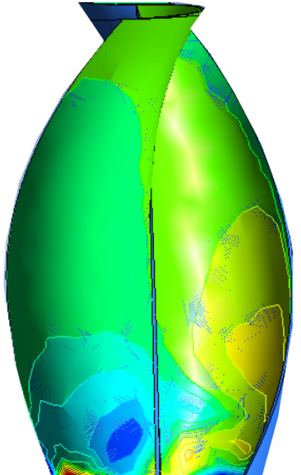

Savonius model

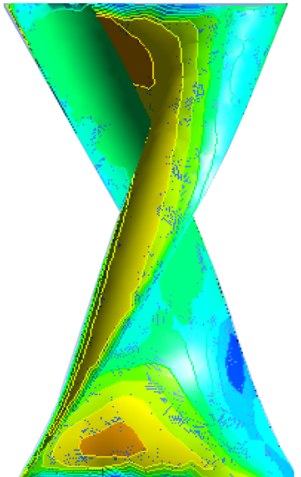

Bach's primary model

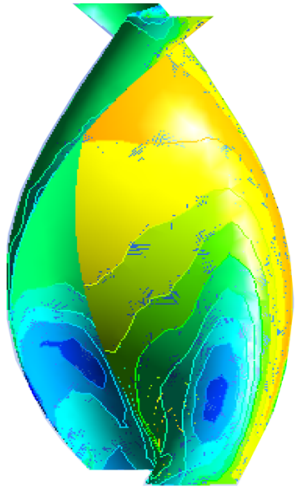

Bach's developed model

\section{c Pressure contour on wind turbine blade at wind speed of $10 \mathrm{~m} / \mathrm{s}$ and rotational speed $250 \mathrm{rpm}$}

Fig. 7 a Pressure contour on wind turbine blade at wind speed of $6 \mathrm{~m} / \mathrm{s}$ and rotational speed $75 \mathrm{rpm}$; b Pressure contour on wind turbine blade at wind speed of $8 \mathrm{~m} / \mathrm{s}$ and rotational speed $150 \mathrm{rpm}$; c Pressure contour on wind turbine blade at wind speed of $10 \mathrm{~m} / \mathrm{s}$ and rotational speed $250 \mathrm{rpm}$ 


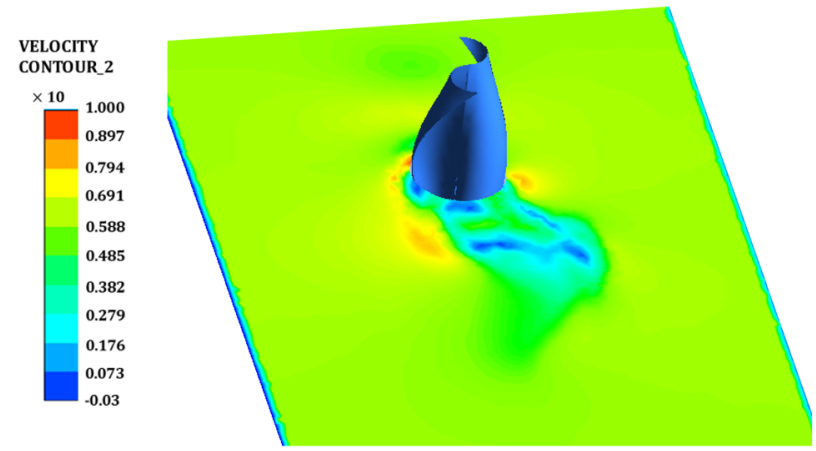

a Downstream flow behind a simple helical Savonius wind turbine at $10 \mathrm{~m} / \mathrm{s}$

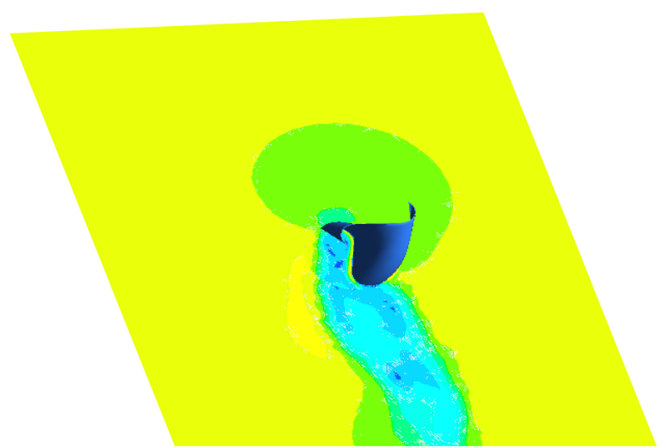

b Downstream flow behind the Bach developed wind turbine at $10 \mathrm{~m} / \mathrm{s}$

Fig. 8 a Downstream flow behind a simple helical Savonius wind turbine at $10 \mathrm{~m} / \mathrm{s}$; b Downstream flow behind the Bach developed wind turbine at $10 \mathrm{~m} / \mathrm{s}$

area has become weaker for the Bach-developed wind turbine at the spoke tip, meaning a perfect wind rotational flow has occurred behind the simple helical Savonius wind turbine, disturbing the wind flow pattern. In contrast, this area has become weaker in the Bach-developed wind turbines.

\subsection{Power coefficient and torque coefficient}

In the operating mode of Savonius turbines, the upwind blades produce positive torque, and the downwind blades produce negative torque. If the result of these torques is positive, the turbine produces positive torque. The relative speed on the downwind blades is the sum of the wind speed and blade speed, but this speed is equal to the difference between wind speed and blade speed for upwind blades. As the blade drag coefficient and the relative speed on it are higher, the greater drag force is applied to the blade, and the blade produces more torque. Typically, the relative speed on the downwind blades is higher than the upwind blades; on the other hand, upwind blades have a higher drag coefficient. As long as the upwind blade torque is higher in contrast between the blade drag coefficient and the relative speed on it, the turbine torque will be positive. By increasing the blade tip speed ratio, the relative speed on the downwind blades increases, and the relative speed on the upwind blades decreases. Thus, the turbine torque becomes negative from a blade tip speed ratio onward. This causes Savonius turbines to be employed in the ranges of low blade tip speed ratios.
Fig. 9 a Power coefficient against the tip speed ratio for three different models at $6 \mathrm{~m} / \mathrm{s}$; b Torque coefficient against the tip speed ratio for three different models at $6 \mathrm{~m} / \mathrm{s}$

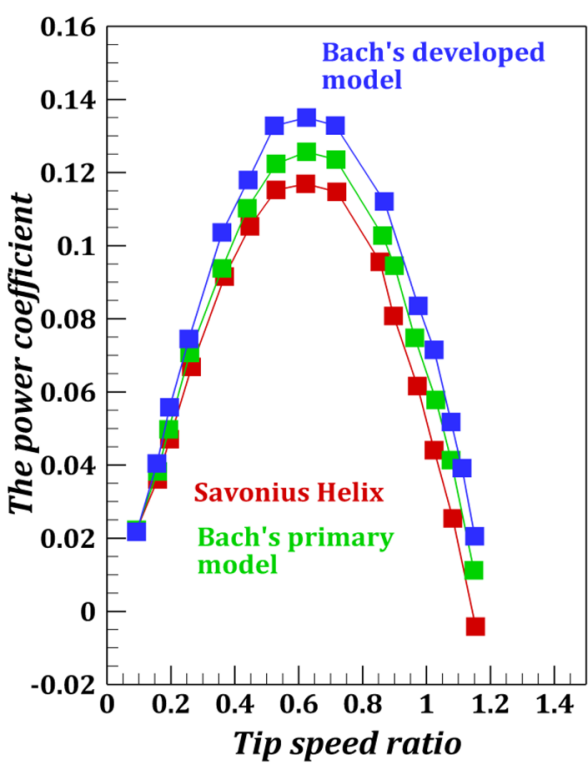

a Power coefficient against the tip speed ratio for three different models at $6 \mathrm{~m} / \mathrm{s}$

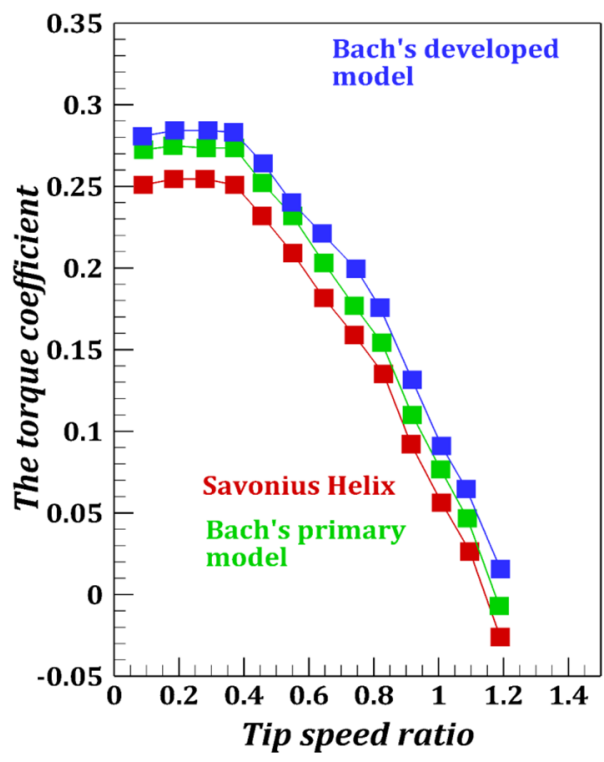

b Torque coefficient against the tip speed ratio for three different models at $6 \mathrm{~m} / \mathrm{s}$ 
Fig. 10 a Power coefficient against the tip speed ratio for three different models at $8 \mathrm{~m} / \mathrm{s}$; b Torque coefficient against the tip speed ratio for three different models at $8 \mathrm{~m} / \mathrm{s}$

Fig. 11 a Power coefficient against the tip speed ratio for three different models at $10 \mathrm{~m} / \mathrm{s}$; b Torque coefficient against the tip speed ratio for three different models at $10 \mathrm{~m} / \mathrm{s}$

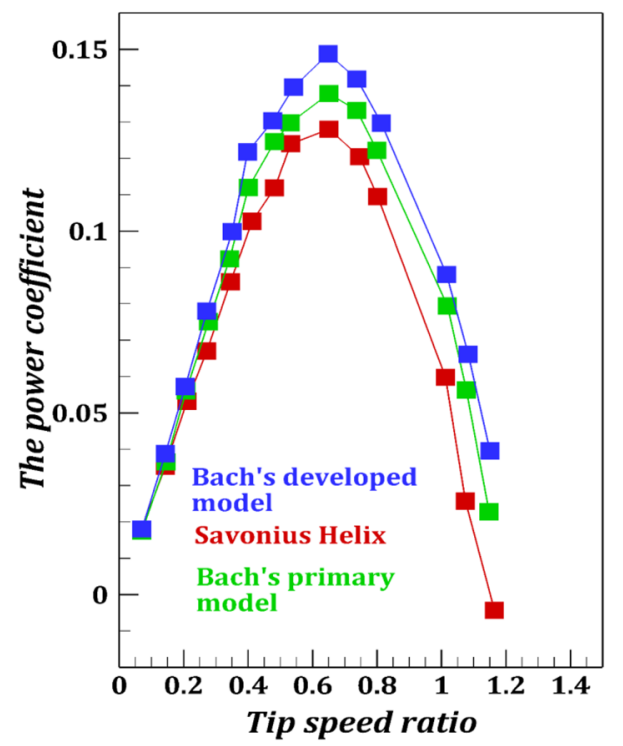

a Power coefficient against the tip speed ratio for three different models at $8 \mathrm{~m} / \mathrm{s}$

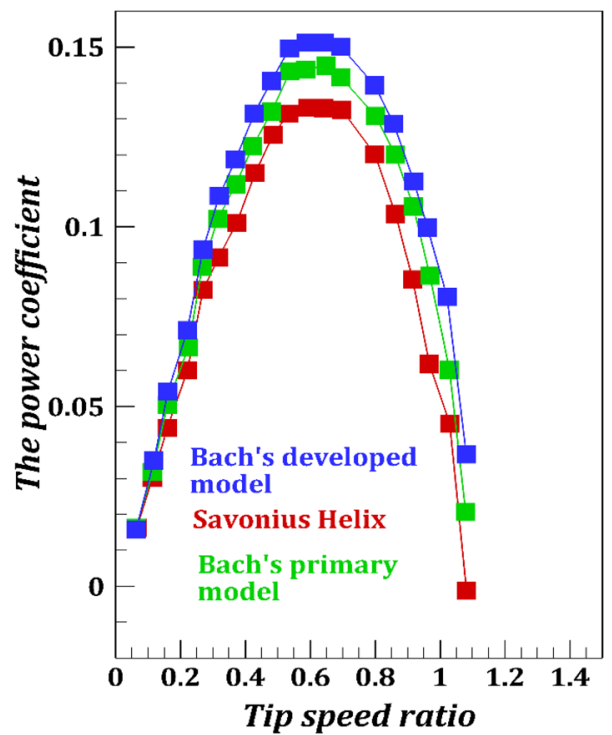

a Power coefficient against the tip speed ratio for three different models at $10 \mathrm{~m} / \mathrm{s}$

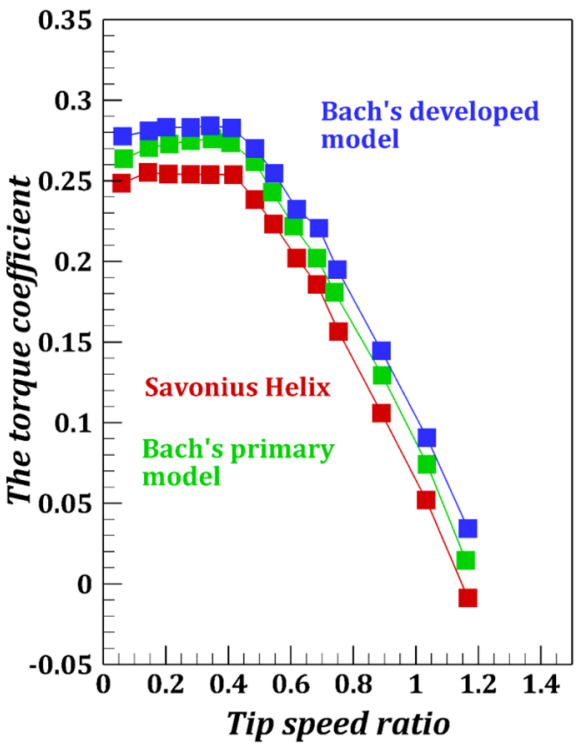

b Torque coefficient against the tip speed ratio for three different models at $8 \mathrm{~m} / \mathrm{s}$

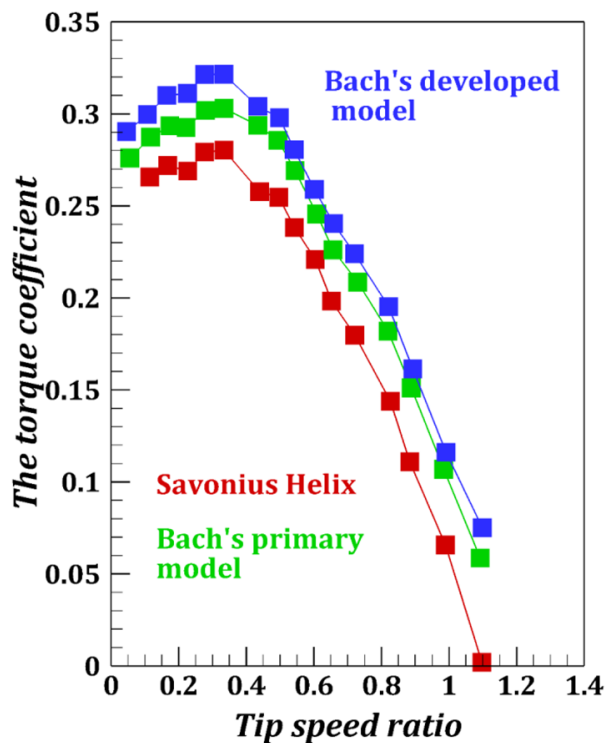

b Torque coefficient against the tip speed ratio for three different models at $10 \mathrm{~m} / \mathrm{s}$ 
Figure 9a shows the ratio of tip speed against the power coefficient at a velocity of $6 \mathrm{~m} / \mathrm{s}$. According to this figure, to some extent, the produced power coefficient increases by increasing the tip speed. After passing through this path and creating the maximum power coefficient, the turbine observes a reduction in this parameter by raising the tip speed. Given the modeling, the presented models have a higher production power coefficient compared to the basic model. Bach-developed models show a $16.1 \%$ performance improvement in the maximum power coefficient. Bach's primary model also offers a $10.21 \%$ power production increase compared with the initial model's best performance. Figure $9 \mathrm{~b}$ shows the torque coefficient changes based on the differences in tip speed ratio. As shown, the tip speed increase reduces the torque coefficient. This issue is predominantly due to increased loads on the turbine rotor shaft, ultimately decreasing torque and velocity.

Figure 10a shows the tip speed ratio against the power coefficient at a velocity of $8 \mathrm{~m} / \mathrm{s}$. The two Bach models in this study offer relatively better performance at $8 \mathrm{~m} / \mathrm{s}$ than function conditions in $6 \mathrm{~m} / \mathrm{s}$, especially during high tip speed velocities. Compared with the basic model, the Bach-developed model shows an $18.3 \%$ performance improvement in the maximum power coefficient. Bach's primary model also offers a $12.4 \%$ power production increase compared to the initial model's best performance. Additionally, Fig. 10b shows torque coefficient changes based on the differences in the tip speed ratio. Based on the previous figure, the rate of relative performance improvement is more than that of the velocity at $6 \mathrm{~m} / \mathrm{s}$ in this diagram.

Figures $11(a-b)$ shows the tip speed ratio against the power coefficient at a velocity of $10 \mathrm{~m} / \mathrm{s}$. There is a significant distance between the production power coefficient and torque coefficient for the two models presented compared to the basic model at this velocity, especially at high tip speeds. However, it is worth mentioning that at this velocity, the performance distance between the two Bach models is much less than the performance at wind velocities of 6 and $8 \mathrm{~m} / \mathrm{s}$. Compared to the basic model, the Bach-developed model shows a $21 \%$ performance improvement in the maximum power coefficient. Furthermore, the highest torque coefficient performance improvement was achieved by the Bach-developed model at $14.8 \%$.

\section{Conclusion}

This study evaluated the wind turbine performance improvement at 6,8 , and $10 \mathrm{~m} / \mathrm{s}$ velocities by changing the Bach section's geometrical dimensions compared to the simple helical Savonius model for the different tip speeds ratios in numerical fluid dynamic environments. The results of this study are categorized as follows:

- Bach-primary and Bach-developed wind turbine models have less flow separation at the spoke's end than the simple helical Savonius model, resulting in a total improvement in wind turbines' performance and reduced spoke dynamic loads.

- The two presented Bach models have a more continuous pressure pattern compared to the basic model. This event demonstrates that the pressure gradient on both sides of the spoke progresses to produces more torque.

- Changing the Bach model's geometry enables wind flow to advance behind the spoke promptly while significantly decreasing rotational flow production behind the turbine.

- The Bach-developed model has the best performance at a $6 \mathrm{~m} / \mathrm{s}$ velocity and a tip speed of 0.6 , compared to the other two models, demonstrating that this model can correct wind flow in the lower hand.

- Performance improvement is more significant in both of the presented models compared to the basic model at a $10 \mathrm{~m} / \mathrm{s}$ velocity, demonstrating the principle that during higher turbulence flows, the helical Savonius basic model is unable to absorb a high amount of power.

- Changing the geometric parameters of the Bach model at high velocities (in turbulent flows) does not significantly affect performance improvement.

Acknowledgements The authors would like to acknowledge the Department of Mechanical Engineering, Babol Noshirvani University of Technology, Iran.

Funding This study received no specific grant from any funding agency within the public, commercial, or not-for-profit sectors.

\section{Declarations}

Conflict of interest The authors declare that there is no conflict of interest.

Ethics approval This article does not contain any experimentation with human participants or animals.

Open Access This article is licensed under a Creative Commons Attribution 4.0 International License, which permits use, sharing, adaptation, distribution and reproduction in any medium or format, as long as you give appropriate credit to the original author(s) and the source, provide a link to the Creative Commons licence, and indicate if changes were made. The images or other third party material in this article are included in the article's Creative Commons licence, unless indicated otherwise in a credit line to the material. If material is not included in the article's Creative Commons licence and your intended 
use is not permitted by statutory regulation or exceeds the permitted use, you will need to obtain permission directly from the copyright holder. To view a copy of this licence, visit http://creativecommons. org/licenses/by/4.0/.

\section{References}

1. Tjahjana DDDP, Arififin Z, Suyitno S, Juwana WE, Prabowo AR, Harsito C (2021) Experimental study of the effect of slotted blades on the Savonius wind turbine performance. Theor Appl Mech Lett S2095-0349:00056-00058. https://doi.org/ 10.1016/j.taml.2021.100249

2. Al-Ghriybah M, Zulkafli MF, Didane DH, Mohd S (2021) The effect of spacing between inner blades on the performance of the Savonius wind turbine. Sustainable Energy Technol Assess 43:100988. https://doi.org/10.1016/j.seta.2020.100988

3. Antar E, Elkhoury M (2020) Casing optimization of a Savonius wind turbine. Energy Rep 6:184-189. https://doi.org/10. 1016/j.egyr.2019.08.040

4. K. Layeghmand, N. Ghiasi Tabari, \& M. Zarkesh, "Improving efficiency of Savonius wind turbine by means of an airfoil-shaped deflector." J Braz. Soc. Mech. Sci. Eng. 42, 528 (2020). https://doi. org/10.1007/s40430-020-02598-7

5. T.Micha Premkumar, S.Sivamani, E.Kirthees, V.Hariram, T.Mohan, "Data set on the experimental investigations of a helical Savonius style VAWT with and without end plates, " Data in Brief, 19 (2018) 1925-1932. https://doi.org/10.1016/j. dib.2018.06.113

6. Stout C, Islam S, White A, Arnott S, Kollovozi E, Shaw M, Bird B (2017) Efficiency improvement of vertical axis wind turbines with an upstream deflector. Energy Procedia 118:141-148. https://doi.org/10.1016/j.egypro.2017.07.032

7. Koroneos C, Spachos T, Moussiopoulos N (2003) Exergy analysis of renewable energy sources. Renew energy 28(2003):295-310. https://doi.org/10.1016/S0960-1481(01)00125-2

8. Baskut O, Ozgener O, Ozgener L (2011) Second law analysis of wind turbine power plants: Cesme, Izmir example. Energy 36:2535-2542. https://doi.org/10.1016/j.energy.2011.01.047

9. Sagol E, Reggio M, llinca A (2013) Issues concerning roughness on wind turbine blades. Renew Sustain Energy Rev 23:514-525. https://doi.org/10.1016/j.rser.2013.02.034

10. Pope K, Dincer I, Naterer GF (2010) Energy and exergy efficiency comparison of horizontal and vertical axis wind turbines. Renew Energy 35:2102-2113. https://doi.org/10.1016/j.renene.2010.02. 013

11. Khalfallah MG, Koliub AM (2007) Effect of dust on the performance of wind turbines. Desalination 209:209-220. https://doi. org/10.1016/j.desal.2007.04.030

12. Nobile R, Vahdati M, Barlow JF (2014) Mewburn-Crook A, "Unsteady flow simulation of a vertical axis augmented wind turbine: a two-dimensional study." J Wind Eng Ind Aerodyn 125:168-179. https://doi.org/10.1016/j.jweia.2013.12.005

13. Al-Ghriybah M, Zulkafli MF, Didane DH, Mohd S (2019) The effect of inner blade position on the performance of the Savonius rotor. Sustain Energy Technol Assess 36:100534. https://doi.org/ 10.1016/j.seta.2019.100534

14. Nimvaria ME, Fatahianb H, Fatahian E (2020) Performance improvement of a Savonius vertical axis wind turbine using a porous defflector. Energy Convers Manage 220:113062. https:// doi.org/10.1016/j.enconman.2020.113062

15. Kragic IM, Vucina D, Milas Z (2020) Computational analysis of Savonius wind turbine modifications including novel scoopletbased design attained via smart numerical optimization. J Clean Prod 262:121310. https://doi.org/10.1016/j.jclepro.2020.121310

16. Akwa JV, Vielmo HA, Petry AP (2012) A review on the performance of Savonius wind turbines. Renew Sustain EnergyRev 16:3054-3064. https://doi.org/10.1016/j.rser.2012.02.056

17. Roy S, Saha UK (2015) Wind tunnel experiments of a newly developed two-bladed Savonius-style wind turbine. Appl Energy 137:117-125. https://doi.org/10.1016/j.apenergy.2014. 10.022

18. Ricci R, Romagnoli R, Montelpare S, Vitali D (2016) Experimental study on a Savonius wind rotor for street lighting systems. Appl Energy 161:143-152. https://doi.org/10.1016/j.apenergy.2015. 10.012

19. Jeon KS, Jeong Jl, Pan JK, Ryu KW (2015) Effects of end plates with various shapes and sizes on helical Savonius wind turbines. Renewable Energy 79:167-176. https://doi.org/10.1016/j. renene.2014.11.035

20. Driss Z, Mlayeh O, Driss S, Driss D, Maaloul M, Abid MS (2015) Study of the bucket design effect on the turbulent flow around unconventional Savonius wind rotors. Energy 89:708-729. https://doi.org/10.1016/j.energy.2015.06.023

21. Lajnef M, Mosbahi M, Chouaibi Y, Driss Z (2020) Performance Improvement in a Helical Savonius Wind Rotor. Arab J Sci Eng 45:9305-9323. https://doi.org/10.1007/s13369-020-04770-6

22. Jradi, M. and S. Riffat, "Tri-generation systems: Energy policies, prime movers, cooling technologies, configurations and operation strategies". Renewable and Sustainable Energy Reviews, 2014. 32: p. 396-415.

23. Sanderse, B., S. Van der Pijl, and B. Koren, "Review of computational fluid dynamics for wind turbine wake aerodynamics". Wind energy, 2011. 14(7): p. 799-819.

24. Gu W et al (2014) Modeling, planning and optimal energy management of combined cooling, heating and power microgrid: A review. Int J Electr Power Energy Syst 54:26-37. https://doi.org/ 10.1016/j.ijepes.2013.06.028

25. Menter FR (1994) Two-equation eddy-viscosity turbulence models for engineering applications. AIAA J 32(8):1598-1605. https://doi.org/10.2514/3.12149

26. Mo, J.-O. and Y.-H. Lee, "CFD Investigation on the aerodynamic characteristics of a small-sized wind turbine of NREL PHASE VI operating with a stall-regulated method". Journal of mechanical science and technology, 2012. 26(1): p. 81-92.

Publisher's Note Springer Nature remains neutral with regard to jurisdictional claims in published maps and institutional affiliations. 